\title{
Course Ideological and Political Education Incorporated Into Teaching Practice and Exploration of "Numerical Computation Method"
}

\author{
Jia Xinxin ${ }^{1 a}$, Wang Lei ${ }^{1}$, Sun Xiaoling ${ }^{1}$, Qiu Huimin ${ }^{1}$, Tang Bo ${ }^{1}$ Miao Wang ${ }^{2}$ \\ ${ }^{I}$ School of Ocean Technology Science, Institute of Oceanographic Instrumentation, Qilu University of Technology \\ (Shandong Academy of Sciences), QingDao, ShanDong, China \\ ${ }^{2}$ School of Management, Qilu University of Technology (Shandong Academy of Sciences), JiNan, ShanDong, China \\ aEmail:jiaxx@qlu.edu.cn
}

\begin{abstract}
According to the teaching characteristics of basic courses in mathematics, this article takes the course of "Numerical Calculation Methods" as the practical research object, and analyze the main problems and causes of course ideological and political education incorporated into teaching. At the same time, in the way of integrating science and education, the strategy and specific implementation plan for the integration of ideological and political elements in the implementation of numerical calculation methods are proposed. It provided new experience and idea for basic mathematics courses in colleges and universities, which will play a role in curriculum ideological and political education.
\end{abstract}

Keywords: Course politics, Teaching exploration, Numerical methods, Science-education Integration

\section{课程思政融入《数值计算方法》教学实践与探索}

贾欣釒金 ${ }^{1 a}$, 王雷 ${ }^{1}$ ，孙小玲 ${ }^{1}$ ，邱慧敏 ${ }^{1}$, 汤博 ${ }^{1}$, 苗旺 ${ }^{2}$

${ }^{\prime}$ 齐鲁工业大学 (山东省科学院) 海洋仪器仪表研究所, 海洋技术科学学院, 青岛, 山东, 中国

2 齐鲁工业大学(山东省科学院) 管理学院, 济南, 山东, 中国

a'Email:jiaxx@qlu.edu.cn

摘要

本文根据数学类专业基础课程的授课特点，以《数值计算方法》课程为实践研究对象，分析了当前课程思政融 入教学中存在的问题及产生原因。同时, 以科教融合的方式, 提出实施数值计算方法课程思政元素融入的策略、 具体实施方案。为高校数学类基础课程, 在课程思政教育课程体系中的完善, 提供了新的经验和思路。

关键词: 课程思政，教学探索，数值计算方法，科教融合

中图分类号：013 文献标志码 A

\section{1. 前言}

在我国, 高等教育肩负这为国家发展及民族复兴 培育人才的重任, 习总书记在我国高等学校思想政治 工作会议上特别强调指出, 高等教育一定要把立德树 人作为首要任务。根据总书记的指示, 需要教育工作 者在平时的教学过程中充分利用好课堂教学这个主 渠道, 将思想政治教育资源充分融入到专业课程教育
中，让专业课课程与思想政治理论课同向同行，使各 种教学力量、各类教育资源、各门课程都能发挥思政 育人功能，形成 “协同效应”。根据总书记关于高等教 育的可以看出, 课程思政就是以结合全体师资、贯穿 整个教育过程、有机融入全体课程的育人新形式, 通 过发掘各类型课程的思政元素结合点和知识结构内 涵, 将思想政治教育有机融合于课堂教学的主渠道, 进而实现立德树人。 


\section{2. 数学类基础课课程思政建设的现状}

目前，国内高校已开始将思想教育融入到各专业 课程教学的不同环节, 专业课的思政教育融合结合了 隐性与显性思政的功能, 也取得了一些教学实践成果 ${ }^{\left[1^{\sim} 5\right]}$ 。但同时也显露出一些问题 ${ }^{\left[6^{2} 8\right]}$, 如我国高校课程科 目涉及面广, 课程思政教学没有统一的模板, 各专业 的课程思政教学有各自的特点, 整体而言思政教学在 数学类基础学科的教学实践中仍然存在一定的问题 以及教学误区, 主要表现为以下几方面:

\section{1. 思政意识不足}

很多数学类基础课授课教师思政教育意识不足, 认为数学类专业基础课跟思政教育关系不大, 课程思 政主要集中在文史类课程的教学过程中, 同时认为思 政教育属于意识形态教育跟基础课相关性不大 “数学 类基础课只要是将理论、应用讲好了就可以了, 跟思 政有关系？”等诸多疑问和认知误区。

\section{2. 思政元素不到位}

课程思政元素引入的不到位, 引发的课程思政内 容的生硬。思政课程授课过程中, 由于没有根据课程 特色、专业特点等因素以及学校的科研状况、文化定 位、地域性文化差异等特点, 造成了思政元素植入效 果欠佳, 进而使得课程思政内容变的生硬、枯燥、牵 强。思政课程不但无法起到正向效果, 相反容易引起 学生的极大反感。

\section{3. 课程规划不到位}

课程思政没有做到持续性与合理规划及思政内 容切入点欠妥当的问题。很多思政课程刚开始开展的 时候, 老师们能够做到图文并茂, 随着时间的推移、 课程时间的增多, 这项内容在授课过程中变少, 甚至 出现偃旗息鼓的情形。这种虎头蛇尾的做事风格, 必 然使得思政课的教学内容大打折扣, 同时也不利于后 续思政课程教学及教学内容反馈、改进工作的开展。 专业课每节 $40^{\sim} 45$ 分钟的时间, 有些思政元素引入时 间不恰当, 如马上就要下课了匀匀加入思政元素, 或 者刚开始上课就引入思政元素。这样不但不能很好的 嵌入和利用思政元素, 相反还容易浪费学生宝贵的课 堂时间。

\section{3. 以《数值计算方法》为例的课程思政内容的 融入和应用}

本文所介绍的课程《数值计算方法》具有较强的 基础学科特点, 该课程是用计算机解决各种数学问题 的一门学科, 是计算机直接解决数学问题的重要基础 工具, 也是高等院校理工科大多数专业学生都必须掌 握的一门实用性极强的基础课程, 本课程可应用于, 数学、物理、电气自动化、光学、电学、经济学、计
算机、软件工程、大数据、人工智能、微电子等专业。 该课程涉及专业极为广泛, 若能够合理成功的开展课 程思政教育, 对于提升理工科专业学生的整体思想认 知水平有显著的效果。

\section{1. 课程思政的设计思路}

课程思政与科研交互融入方面, 可以根据《数值 计算方法》课程与科研实践相结合的特点, 用高等数 学、线性代数等先修课程的知识作为基础, 结合各专 业方向遇到的一些科研实例与工程实践, 引导学生使 用所学数学理论思路实现算法设计及计算误差分析, 同时对数值运行结果进行理论分析与实验验证相结 合的验证方式，根据不同教学内容进行不同方式与不 同视角的科教融合与课程思政实践活动。

课程思政的切入设计方面，在数值方法专业知识 学习过程中以具体算法对于科学研究、工程实践应用 为实例主题，合理融入思政元素，达到 “润思政” 且 “细无声”, 自然融合的效果。根据所讲数值计算方 法具体特点, 以科研实例、科研人物、工程应用等作 为切入点, 自然地将该课程的教学知识点和思政元素 有机结合。

目前, 学院课题组在前期思政教育教学基础上, 对当前所做课程思政工作进行了梳理及总结, 同时结 合本校科教融合海洋学院各专业特色进行了教学改 革和教法革新, 得到了一些关于思政课程的经验与素 材。

《数值计算方法》授课中课程思政元素融入课程 的教学建设思路（见图 1) 所示:

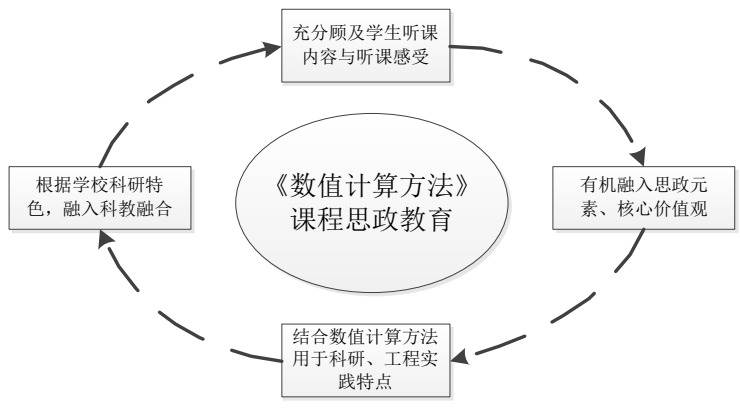

图 1 课程思政建设思路

具体教学思政元素合理穿插融入教学过程的设 计如图 2 所示: 


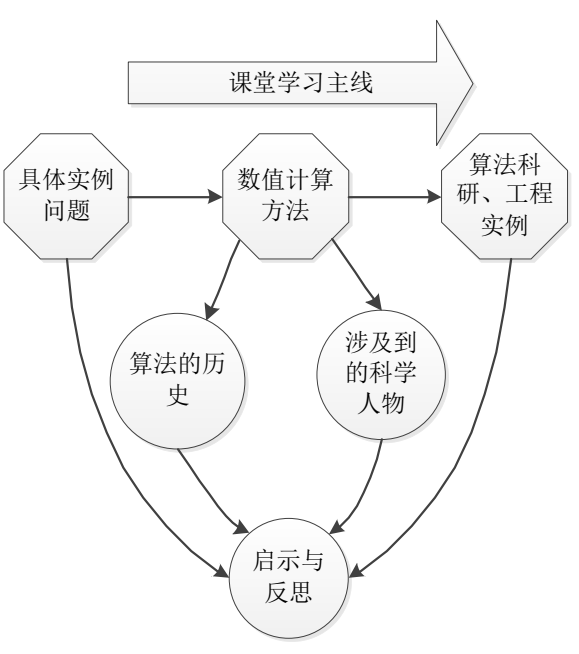

图 2 思政课程内容设计

\section{2. 课程思政的设计方法}

下面将数值计算方法结合具体思政元素案例展 开分析:

(1). 将数值计算方法与我国科技发展结合，培 养学生的使命责任感, 激发爱国热情培养家国意识。 在各章节介绍过程中插入自制课程短片, 介绍现代科 技随着大数据、人工智能、 $5 \mathrm{G}$ 信息传输技术的发展, 科学技术的制高点已发生改变。课程中引入时政元素, 2019 年美国开始利用各种手段打压中国的高科技通 讯企业, 如华为、中兴、腾讯等公司, 因为随着信息 技术的发展, 影响未来科技的关键要素已经变为数据、 信息, 有效获取数据、信息依赖 3 个要素: 算法、算 力、数据流量, 这其中算法占据核心地位, 因此计算 机算法在技术领域中格外重要。通过引入现实中的例 子, 如中国字节跳动公司的子公司, 通过成功开发 TikTok 手机软件, 在短短两年时间内成长为一个世界 级公司, 而该公司软件极具竞争力的关键就在于软件 所采用的视频算法。通过生活中的鲜活实例, 真正的 让学生体会到学习该课程的重要性。在爱国热情培养 方面, 美国对中国科技公司的疯狂打压, 也反应出我 国科技水平的巨大潜力, 这样触动学生的心灵, 激起 学生对生活在新时代以及有我们强大的祖国作为发 展平台而自豪, 增加为祖国科技进步而继续努力的使 命感和责任感。

(2). 将数值计算方法的基本理论与应用案例结 合, 合理增加思政元素。在给学生讲解线性方程组的 迭代法时, 引入导航芯片的简化电路图, 根据电路图 推导出电流方程组, 通过雅克比迭代法求解电路电流。 由此融入思政元素, 一块小小的芯片, 内部构造极为 复杂, 由千万级的电路组成, 如此小的一块高精度 $\mathrm{nm}$ 级芯片我国居然生产不了, 因为我们缺少了生产工具 - 一光刻机, 由此引出我国科技发展, 时常被欧美国 家 “卡脖子”。因此告诫同学们 “科学无国界, 技术有 国别”, 真正的技术是买不来的, 我们只有学好知识、 技术才能不被其他国家卡脖子, 依次培养学生的爱国
情怀及学习使命感。

(3). 将我国的数学史与数学文化合理融入, 培 养民族自豪感以及文化自信。数值计算方法教学过程 中, 将数学的美育价值与思政元素合理、有机融合, 引导学生扎根华夏土地、励志科技报国, 进而激发学 生投身科研、热爱科学的热情。在学习函数插值与拟 合时, 介绍我国隋朝学者、天文学家, 刘焯已将等距 二次插值, 用于计算日月视差运动速度, 推算出五星 位置和日、月食的起运时刻, 这是中国历法史上重大 突破, 他编有《皇极历》。学习多项式计算时, 重点介 绍我国南宋杰出数学家秦九韶, 他的《数书九章》概 括了该时期我国传统数学的主要成就, 用此以增强学 生的文化自信。

\section{4. 促进课程思政的实施思路}

\section{1. 师资队伍的建设}

在教学活动期间, 进一步加强针对基础课教师的 思想政治教育与培训, 使其从认知的源头增强其 “道 路、理论、制度、文化等的自信”，进一步培养教师的 育人意识, 使教师从心底热爱教学、热爱学生、热爱 教育事业。在专业知识方面, 夯实自身所具备的的专 业基础知识, 在传授课程的同时为学生树立正向的价 值榜样。改变传统的老师只负责具体知识传授的观念, 引导教师合理利用课程思政的契机，开展课堂的思想 政治教学与培养。同时利用各类方法加强课程思政教 学改革工作, 引导教师通过具体方式, 把知识传授、 能力培养、思想引领真正融入数值计算方法等各类基 础课的课程教学过程中。

\section{2. 各类教学手段的合理利用}

在行动上以 “以学生为中心”, 推进基础课程的 课堂教学模式改革。具体的教学手段上, 注重使用最 新的教辅工具, 如合理使用 “雨课堂” 等最新教学工 具辅助教学, 将需要预习的内容在课前及时推送给学 生, 同时提出一系列与课程内容及思政内容相关联的 问题, 启发学生的思考, 同时在课堂上使用雨课堂及 时接收反馈的知识掌握信息。结合课堂教学过程中的 具体教学内容, 同时根据学生需要思考和解决的具体 知识点, 开展具体的课程思政内容, 进而从内容上引 导学生的合理参与。使用雨课堂等工具, 对课程过程 中的知识学习、思维训练、课后作业等信息反馈与数 据分析统计，加强教学活动的持续改进。

\section{3. 教学实践活动的开展}

在数值计算方法课程的教学过程中, 增加科教融 合元素, 引入平时科研中存在的问题, 以问题为导向 使学生深入研究各类数值计算算法。使学生从根本上 意识到, 实践是检验真理的唯一标准, 科学的计算方 法需要科学问题进行实践验证, 对思政元素, 使学生 
产生自觉的理解和认同。

\section{4. 合理挖掘数值计算方法的思政元素}

数值计算方法等基础类学科, 有着悠久的历史, 作为理工科研究、认知的重要工具, 很适合融入思政 元素。因此要求教师在教学过程中, 应充分挖掘基础 类学科的文化、历史、人物等元素作为本课程的思政 元素, 形成完整的教学案例, 合理修改与调整教学大 纲, 将基础类专业课程内容合理的融入思政课程的课 堂。

\section{5. 结论}

大学阶段数学类专业基础课课程思政的开展, 目 的是通过教师挖掘相关数学类基础课程的思想政治 资源, 在课程的讲述过程中通过科教融合、教学理论 与具体案例结合, 以及数学文化的融入等方式, 合理 的对大学生们进行思政教育。这些教学方式, 一方面 引导学生形成正确的人生观、价值观, 培养其家国情 怀; 另一方面让更多学生了解我国的数学发展历史, 培养学生的文化自信心, 同时激发学生投身科研、热 爱科学的热情。

\section{项目基金}

本文为山东省本科教学改革研究项目 “《基于金 课建设理念的线上课程思政研究与实践》” (M2020151). 齐鲁工业大学 (山东省科学院), 教改思 政项目 (2020szzx11、2020szzx12), 科教融合项目 （2020kjzx04）的阶段性研究成果之一.

\section{作者简介}

贾欣金金 (1983-), 男, 山东青岛人, 工学博士, 齐 鲁工业大学 (山东省科学院) 海洋技术科学学院, 讲 师, 研究方向为数值计算、流动数值计算.

\section{REFERENCES}

[1] MIN Jie, LI Yibao. Research on Combining style Teaching Methods in College Numerical
Analysis[J]. Higher Education Forum , 2010(6):72-74.

[2] Chen Aibin, Zhang Zhaoyuan. Teaching Research and Discussion on "Numerical Analysis" Course of Artificial Intelligence Major[J] Computer Education, 2019(10):71-73.

[3] Qin Hourong, Xu Hairong. The "touch points" of college mathematics curriculum ideology and politics and the construction of teaching system [J]. Chinese university teaching, 2019(9):61-64.

[4] Liu Sanming. Teaching research and practice of "Numerical Analysis" based on innovation and application ability $[\mathrm{J}]$. University Education, 2016(2):130-131.

[5] Gong Dianxuan, Peng Yamian, Zheng Shiqiu. Practice and Ideas of Teaching Reform of "Numerical Analysis" Course [J]. Mathematics Learning and Research, 2019(19): 52-54.

[6] Shao Xinhui, Feng Nan, Shi Datao. Teaching Exploration of Numerical Analysis Based on Curriculum Ideology and Politics[J].Journal of Liaoning Institute of Educational Administration, 2020(5):27-29.

[7] Wang Guoding, Luo Ping. Exploration and Practice on Incorporating the Concept of Course-based Ideological and Political Education into the Teaching of Higher Algebra [J].The Science Education Article Collects, 2021(07):78-80.

[8] Wang Lia, Peng Zhuohua, Wang Tao, et al. Teaching $\mathrm{R}$ eform and Practice of Computational Methods Course under Background of "New Engineering": Taking Hunan University of Science and Technology as an Example[J]. Theory and Practice of Contemporary Education, 2021(05):2021. 